\title{
Stress-induced anisotropy in sand under cyclic loading
}

\author{
Minyun Hu • Catherine O'Sullivan • \\ Richard R. Jardine • Mingjing Jiang
}

Received: 17 December 2009 / Published online: 7 September 2010

(C) The Author(s) 2010. This article is published with open access at Springerlink.com

\begin{abstract}
The anisotropy of a granular material's structure will influence its response to applied loads and deformations. Anisotropy can be either inherent (e.g. due to depositional process) or induced as a consequence of the applied stresses or strains. Discrete element simulations allow the interactions between individual particles to be explicitly simulated and the fabric can be quantified using a fabric tensor. The eigenvalues of this fabric tensor then give a measure of the anisotropy of the fabric. The coordination number is a particle scale scalar measure of the packing density of the material. The current study examines the evolution of the fabric of a granular material subject to cyclic loading, using two-dimensional discrete element method (DEM) simulations. Isotropic consolidation modifies and reduces the inherent anisotropy, but anisotropic consolidation can accentuate anisotropy. The
\end{abstract}

\section{Hu}

Key Laboratory of Geotechnical and Underground Engineering of Ministry of Education, Tongji University, Shanghai, China

\section{Hu ( $\square)$}

College of Civil Engineering and Architecture, Zhejiang University of Technology, Hangzhou 310014, China

e-mail: huminyun@zjut.edu.cn

C. O'Sullivan · R. R. Jardine

Department of Civil \& Environmental Engineering, Imperial College London, Skempton Building, South Kensington Campus, London SW7 2AZ, UK

e-mail: cath.osullivan@imperial.ac.uk

R. R. Jardine

e-mail: r.jardine@imperial.ac.uk

\section{Jiang}

Department of Geotechnical Engineering, Tongji University, 1239 Siping Road, Shanghai 200092,

China

e-mail: mingjing.jiang@tongji.edu.cn ratio of the normal to shear spring stiffness at the particle contacts in the DEM model affects the evolution of anisotropy. Higher ratios reduce the degree of anisotropy induced by anisotropic consolidation. The anisotropy induced by cyclic loading depends on the amplitude of the loading cycles and the initial anisotropy.

Keywords Sand · Anisotropy · Discrete element method . Fabric tensor

\section{Introduction}

There are many situations where soil is subject to extended periods of drained cyclic loading. Practical foundation scenarios involving drained cyclic loading include road pavements (e.g. Lekarp et al. [1]), reciprocating machines and storage tanks (Sweeney and Lambson [2]) as well as offshore and wind turbine foundations. Other examples are offered by the soil backfill adjacent to integral bridge abutments (e.g. Clayton et al. [3]) and earth dams subject to reservoir level fluctuations (Tedd et al. [4]). Janbu and Seneset [5] proposed that observed time-dependant settlements of structures on high permeability soils may be due to combined effects of cumulative displacements under cyclic loading and creep. Jardine et al. [6] noted important interactions between ageing, creep and cyclic loading in field tests on piles driven in sand. Piles that could be brought to failure by high level drained cyclic loading could also show a benign or even beneficial response to low level drained cycling. A fundamental understanding of the processes that define cyclic stiffness, the growth of permanent deflections, the potential effects on creep and implications for failure loads would offer significant practical benefits. This paper reports a contribution that focuses on drained load cycling in high permeability granular 
media. A simplified and idealized system is considered that offers insight into evolution of fabric and stress anisotropy under extended cyclic loading.

Anisotropy of soils can be classified into two components: inherent anisotropy and stress induced anisotropy. Inherent anisotropy is attributed to preferred particle and contact orientations that develop during deposition. Stress-induced anisotropy, on the other hand, results from the deformation associated with different changes in applied stress. Oda et al. [7] listed three approaches to quantify anisotropy in a granular material: (1) distribution of contact normal orientations, (2) the orientation of void spaces; and (3) the orientation of nonspherical particles. Moreover, Oda et al. observed that the inherent anisotropy due to (1) and (2) can be altered during the early stage of inelastic deformation, while the inherent anisotropy due to (3) persists even after shearing to large strains.

Motivated by the need to advance understanding of liquefaction, a significant number of research studies have examined the response of soil to undrained cyclic loading. Fewer studies have examined the response to many cycles of drained cyclic loading. Recent experimental studies considering the response of sand to repeated loading in drained conditions include the work of Cosgrove et al. [8], AnhDan and Loseiki [9], Wichtmann et al. [10], Wichtmann and Triantafyllidis [11] and Festag and Katzenbach [12]. While these experimental studies have provided insight into the overall material response, the issue of soil fabric has not been considered in detail. Other studies on the mechanical response of soil indicate that fabric must be carefully considered. For example, Hyde et al. [13] studied the behavior of silt following undrained cyclic loading and found that initial anisotropy can affect postcyclic recompression, stiffness, and consolidation strength of soil. A better understanding of the evolution of soil micro-structure under cyclic loading is required to improve fundamental understanding of soil response and hence our ability to predict deformations. The development of constitutive models that include fabric parameters is ongoing. For example, Papadimitriou and Bouckovalas [14] developed an analytical approach to account for fabric changes during cyclic loading in a continuum elasto-plastic constitutive model.

One approach that can be adopted to gain data on fabric evolution is to simulate the response of assemblies of particles using the distinct element method (DEM) as proposed by Cundall and Strack [15]. In DEM, the individual particles are simulated and simple contact laws are used to describe their interactions. Then, the system evolution is obtained by integrating the equations of motion for each particle. There have been limited applications of DEM to study the cyclic response of granular materials. Using DEM, David et al. [16] studied the effect of cyclic loading on the development of strain within a granular material, demonstrating significant strain accumulation with increasing number of cycles. O'Sullivan et al. [17] simulated drained strain controlled cyclic triaxial tests. Good agreement was found between the DEM simulations and physical tests on an ideal granular material. The material's internal structure continued to evolve during cyclic loading and the variation in fabric was found to depend on the applied strain level.

The current study investigated the evolution of anisotropy of sand during stress controlled drained, cyclic loading. 2D circular disk particles were used allowing the stress induced anisotropy given by the contact normal orientations to be isolated. A parametric study considered different interaction parameters, different consolidation states, and different cyclic stress amplitudes.

\section{Fabric tensor}

A convenient means to quantify the overall orientation of the contact normals in a granular material is the fabric tensor. Key references describing the use of the fabric tensor to characterize the fabric of granular materials include Satake [18], Rothernberg and Bathurst [19], Oda [20], and Oda et al. [7]. There are subtle differences in the equations presented in the literature for the fabric tensor. The expression for the 2 nd order (2nd rank) fabric tensor adopted here follows that used by Thornton [21] and is given by:

$\Phi_{i j}=\frac{1}{N_{c}} \sum_{N_{c}} n_{i} n_{j}$

where $\Phi_{i j}=$ fabric tensor; $N_{c}=$ number of contacts; $n_{i}=$ unit vector normal to contact. The matrix form of fabric tensor in $2 \mathrm{D}$ is

$\Phi=\frac{1}{N_{c}}\left[\begin{array}{ll}\sum_{N_{c}} n_{1} n_{1} & \sum_{N_{c}} n_{1} n_{2} \\ \sum_{N_{c}}^{N_{2}} n_{2} n_{1} & \sum_{N_{c}} n_{2} n_{2}\end{array}\right]$

Similar to the stress tensor, $\sigma$, the eigenvalues of this matrix give the principal values of fabric: $\Phi_{1}$ and $\Phi_{2}$. The difference between the maximum and minimum eigenvalues $\Phi_{1}-\Phi_{2}$, is defined as the deviator fabric, and this parameter quantifies the anisotropy of the material. An isotropic material will have $\Phi_{1}=\Phi_{2}=0.5$.

A second (scalar) measure of fabric is the coordination number, this gives the density of contacts in the system and is calculated as

$Z=\frac{2 N_{c}}{N_{p}}$

where $N_{c}$ is the total number of contacts and $N_{p}$ is the number of particles. 


\section{Materials and methods}

\subsection{Sample preparation}

A sample of circular disks, with diameters between 0.20 and $0.50 \mathrm{~mm}$ was created within the two-dimensional DEM code PFC 2D. The initial particle coordinates were determined by digitizing photographs of physical biaxial compression tests on "Schneebeli" rod specimens described by Thomas [22]. A uniform scaling was then applied to the particle sizes and positions to reduce the particle radii to sizes closer to real soil. A monotonic simulation using this input configuration is described by O'Sullivan et al. [23]. The specimen configuration is illustrated in Fig. 1. The sample was restricted to contain a relatively small number of particles (896) so that large numbers of quasi-static load cycles could be completed within a reasonable time. Referring, for example, to the discussion on DEM specimen generation by Marketos and Bolton [24], for the simulation presented here each particle in the assembly was in a stable position under gravitational loading. Consequently the sample possessed an inherent anisotropy prior to the application of a stress field within the DEM simulation. To achieve a specified stress state the sample was enclosed between 4 rigid walls. The wall positions were then adjusted in a servo-controlled manner to bring the sample to an initial stress state. Both isotropic and " $\mathrm{K}_{0}$ " initial stress states were considered. Once the specified stress state had been achieved the lateral rigid walls were removed and a numerical membrane was introduced. This numerical membrane finds the disks on the outside of the sample and applies a force to each disk to achieve a specified confining pressure $[25,26]$.

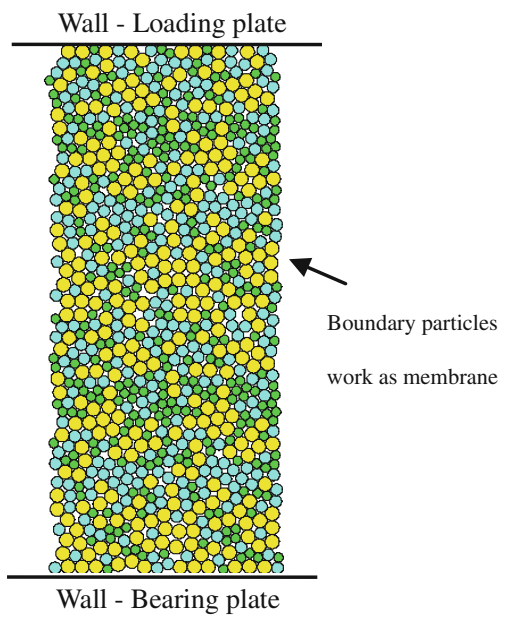

Fig. 1 Sample for DEM analysis

\subsection{Model and parameters}

The simple linear-elastic contact law provided in PFC2D and commonly used in DEM analysis was adopted in this study. While more sophisticated models are available, the linear model was considered adequate for the 2D simulations considered here. In the simulations the particles interact only if they are in contact, and the force between them can be decomposed into a normal and a tangential part. The normal and tangential spring stiffness between particles were selected to be either $\mathrm{k}_{\mathrm{n}}=\mathrm{k}_{\mathrm{s}}=2 \times 10^{7} \mathrm{~N} / \mathrm{m}$ or $\mathrm{k}_{\mathrm{n}}=3 \times 10^{7} \mathrm{~N} / \mathrm{m}$. The linear contact springs here are viewed as "penalty springs", chosen to be sufficiently stiff to minimize overlap at the contact points and to minimize the tangential displacement prior to shearing. While this approach is valid for a $2 \mathrm{D}$ analysis considering finite strains, it should be adopted with caution when small strain response is under consideration. Yimsiri and Soga [27] propose a expression for the overall elastic properties of a granular material in terms of the normal and tangential spring stiffnesses, and demonstrate that if $\mathrm{k}_{\mathrm{n}}=\mathrm{k}_{\mathrm{s}}$ the resultant Poisson's ratio will be zero, which is obviously an unreasonable value. The damping coefficient adopted for the simulations was 0.7 , using the default value for the local damping available within PFC and described by Itasca [28]. Care was taken to ensure that the simulations were quasi-static and not overdamped by ensuring that the total forces measured on the top and bottom boundaries were equivalent throughout the simulation. Interaction forces also exist between particles and loading/bearing plates. The normal and tangential stiffness used were $\mathrm{k}_{\mathrm{n}}^{\mathrm{W}}=\mathrm{k}_{\mathrm{s}}^{\mathrm{W}}=1.94 \times 10^{7} \mathrm{~N} / \mathrm{m}$, while the particleboundary friction coefficient was $\mathrm{f}_{\mathrm{s}}=0.0875$.

\subsection{Test procedure and project}

In order to examine the induced anisotropy in granular material by cyclic loading, the effects of consolidation process

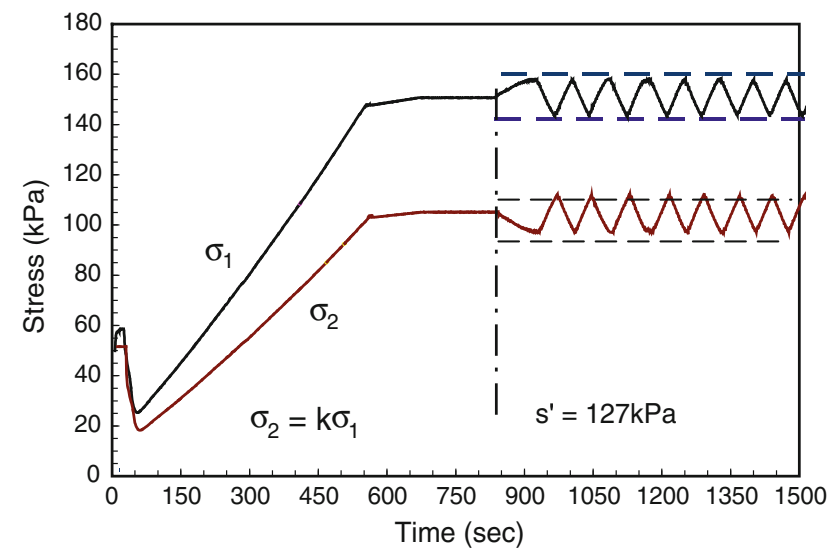

Fig. 2 Typical load path of cyclic loading 
Table 1 Testing program for cyclic loading

\begin{tabular}{lllll}
\hline Test number & Sample size $\mathrm{b} \times \mathrm{h}(\mathrm{mm} \times \mathrm{mm})$ & Initial consolidation & $\begin{array}{l}\text { Ratio of con- } \\
\text { tact stiffness } \\
\mathrm{kn} / \mathrm{ks}\end{array}$ & $\begin{array}{l}\text { Cyclic } \\
\text { stress level } \\
\Delta \mathrm{t} / \mathrm{s}^{\prime}\end{array}$ \\
\hline T20 & $10 \times 23(896$ particles $)$ & Anisotropic $K=\sigma_{2}^{\prime} / \sigma_{1}^{\prime}=0.69$ & 1.0 & 0.02 \\
T30 & $10 \times 23(896$ particles) & Anisotropic $K=\sigma_{2}^{\prime} / \sigma_{1}^{\prime}=0.69$ & 1.0 & 0.03 \\
T40 & $10 \times 23(896$ particles) & Anisotropic $K=\sigma_{2}^{\prime} / \sigma_{1}^{\prime}=0.69$ & 1.0 & 0.04 \\
T41 & $10 \times 23(896$ particles $)$ & Anisotropic $K=\sigma_{2}^{\prime} / \sigma_{1}^{\prime}=0.69$ & 1.5 & 0.04 \\
T400 & $10 \times 23(896$ particles $)$ & Isotropic & 1.0 & 0.04 \\
T401 & $10 \times 23(896$ particles $)$ & Isotropic & 1.5 & 0.04 \\
\hline
\end{tabular}

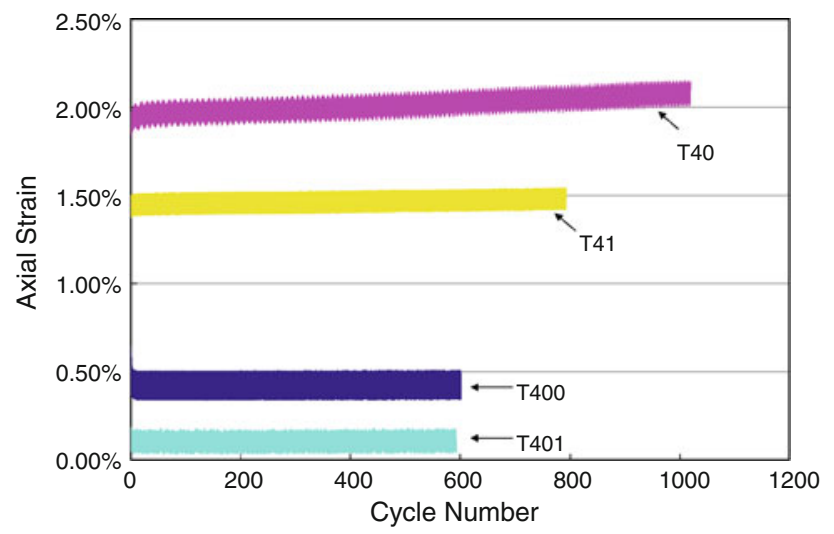

Fig. 3 Axial strain against cycle number after isotropically and anisotropically consolidated

and contact stiffness were investigated. From an initial isotropic stress state of $50 \mathrm{kPa}$, the samples were either isotropically or anisotropically consolidated under a mean normal effective stress $\mathrm{s}^{\prime}=\left(\sigma_{1}^{\prime}+\sigma_{2}^{\prime}\right) / 2$ (for this $2 \mathrm{D}$ analysis $)=127 \mathrm{kPa}$. Then, maintaining a constant $\mathrm{s}^{\prime}$ value, each sample was cyclically loaded to increase the deviator stress $\mathrm{t}$ $=\left(\sigma_{1}^{\prime}-\sigma_{2}^{\prime}\right) / 2$ by between $0.02 \mathrm{~s}^{\prime}$ and $0.04 \mathrm{~s}^{\prime}$ (Fig. 2 ). The load cycles were applied in a servo controlled manner by moving the top wall upwards and downwards with a constant velocity of $0.01 \mathrm{~mm} / \mathrm{s}$ and monitoring the stresses induced in the sample. The testing programme adopted is shown in Table 1.

\section{Numerical results}

\subsection{Effect of consolidation process}

The consolidation process adopted generated samples with different anisotropies, and these are the initial anisotropies for the samples prior to the application of the load cycles. The differences in fabric resulted in a variation in the overall material response to equivalent applied stresses. Figure 3 shows the variations of axial strain with the number of cycles for both the isotropically and anisotropically consolidated samples loaded with an amplitude of $\Delta \mathrm{t} / \mathrm{s}^{\prime}=0.04$. Note

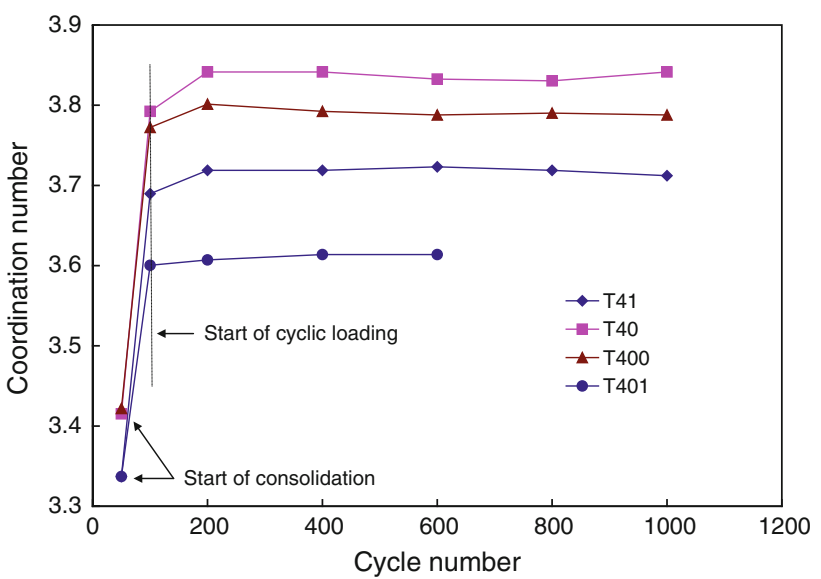

Fig. 4 Coordination variation with cycle number: influence of stress history and contact spring stiffness ratio

that the axial strain values are measured taking the original sample height prior to consolidation. It was seen that the axial strain tended to accumulate with increasing numbers of cycles number in the anisotropically consolidated samples, i.e. T40 and T41, although the rate of accumulation was more rapid in $\mathrm{T} 40$ which had the higher $\mathrm{k}_{\mathrm{n}} / \mathrm{k}_{\mathrm{s}}$ ratio. However, in the isotropically consolidated samples, i.e. T400 and T401, little axial strain accumulation was observed over the 1,000 cycles considered. The relative stability of the isotropically consolidated samples can be attributed to the greater lateral support to the strong force chains offered by the contacts orientated orthogonal to the applied deviatoric stress, in comparison to the anisotropically consolidated sample.

Figures 4 and 5 present the changes of coordination number, Z, and deviator fabric, $\Phi_{1}-\Phi_{2}$ respectively, against cycle number. From Fig. 4, it can be observed that, at the end of consolidation, samples subject to an anisotropic stress state, e.g., T40, have a higher coordination number than the isotropic samples, e.g., T400. While this means there are more contacts in the system as a whole, the anisotropic stress state will mean that the lateral contacts supporting the strong force chains are more lightly loaded, and consequently less stable in comparison with the isotropically consolidated sample. In Fig. 5, we can see clearly the anisotropy evolution during 


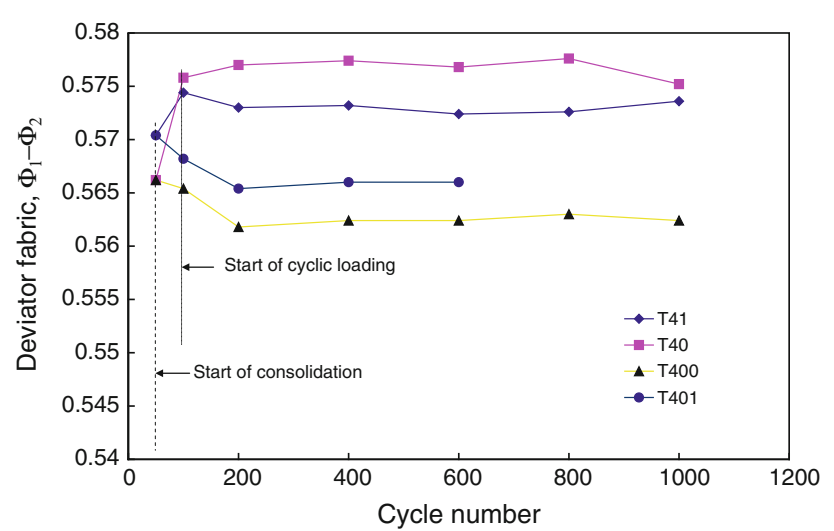

Fig. 5 Deviator fabric variation with cycle number: influence of stress history and contact spring stiffness ratio

loading. It is interesting to observe that during two different consolidation process the deviator fabric changed in different ways (compare T40 and T400). At the start point of consolidation, both samples were identical with the same amount of inherent anisotropy. However, during consolidation, the deviator fabric increased in T40, which was anisotropically consolidated, while in T400, the deviator fabric decreased as the sample was isotropically consolidated. These observations suggest that the inherent anisotropy of a granular soil may be increased by further anisotropic loading and partially erased by isotropically loading. This agrees with some of the observations by Oda (1985) for biaxial compression of photoelastic disks. Considering the results presented in Fig. 5, during the first 200 cycles, the deviator fabric kept increasing in T40, and conversely, it decreased continuously in T400. Since the samples were cyclically sheared under a constant mean stress, i.e. $\mathrm{s}^{\prime}=127 \mathrm{kPa}$, it suggests that the stress history during consolidation affects the anisotropy evolution during deviatoric loading. The increase in anisotropy correlates with the higher rate of strain accumulation during cyclic loading.

\subsection{Effect of contact stiffness}

When an assembly of particles is stressed, the inter-particle forces and the deformation of the contact force network depend largely on the contact stiffness between the particles. The contact stiffness is composed of two parts: a normal and a tangential stiffness. Not only do the values of normal and tangential stiffness affect soil behavior, but their ratio also influences the response. The results presented in Fig. 3 indicate that the samples with the higher ratio of $k_{n} / k_{s}$, i.e. T41 and T401, offer a greater resistance to axial deformation. Figure 4 indicates that T41 and T401 can remain stable with a smaller coordination number. This can be explained by the fact that both the normal and tangential contact springs will contribute to the horizontal and vertical stress transmission.
When the normal contact spring stiffnesses are increased this will attract a greater proportion of the contact forces to be transmitted by the normal contact springs, i.e. in the contact normal direction. This redistribution of load will mean that these contacts have both a greater resistance to sliding, and smaller tangential forces driving sliding, with a resultant increase in stability.

The evolution of anisotropy is illustrated in Fig. 5. The samples with $\mathrm{k}_{\mathrm{n}} / \mathrm{k}_{\mathrm{s}}=1.5$, i.e. T41 and T401, had a higher deviator fabric at the start of consolidation than the samples with $\mathrm{k}_{\mathrm{n}} / \mathrm{k}_{\mathrm{s}}=1.0$, i.e. $\mathrm{T} 40$ and $\mathrm{T} 400$, indicating a stronger initial anisotropy. During the consolidation process, both isotropically consolidated samples T401 and T400 exhibited a similar decrease of anisotropy but T401 maintained a higher deviator fabric value than T400 throughout. During the anisotropic consolidation process the deviator fabric increased in sample T41, but the increase was smaller than that observed in T40. Raising the contact stiffness ratio reduces the rate of evolution of anisotropy under anisotropic loading despite the level of initial anisotropy. During the first 200 cycles, both T41 and T401 showed a decrease in deviator fabric, indicating pure deviator stress cycles may partially reduce the initial anisotropy. Note that in sample T41 the deviator fabric remained above the value for the inherent anisotropy prior to consolidation indicating that the contact orientations retain a "memory" of the consolidation stress history.

\subsection{Effect of cyclic stress amplitude}

Figure 6 illustrates the variation of axial strain with the number of cycles for samples with different cyclic stress amplitudes. These simulations consider a greater number of stress cycles than those presented in Fig. 3 (with a maximum value of 5,000 load cycles, rather than 1,000). Within each loading cycle the axial strain varied with the deviatoric stress. The low level cyclic test showed a broadly stable response with little permanent straining. In contrast, the sample with the highest $\Delta \mathrm{t}^{\prime}$ value progressed to some form of local failure after 4,000

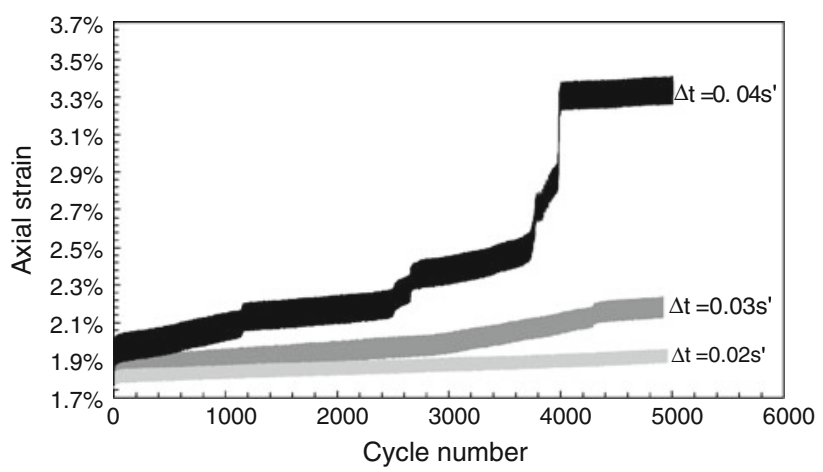

Fig. 6 Variation in axial strain with cycle number for three different amplitudes of cyclic loading 


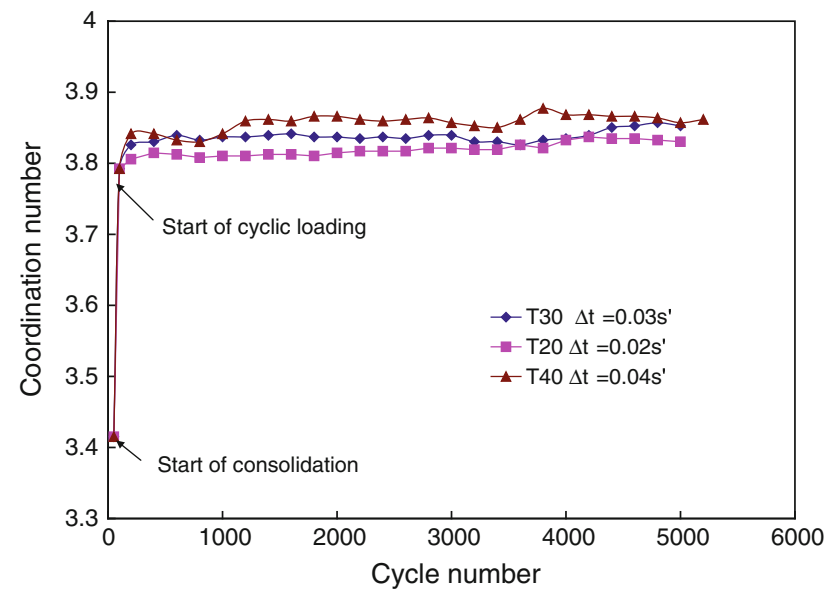

Fig. 7 Variation in coordination number during cyclic loading for different stress amplitudes

cycles. This failure can most likely be attributed to collapse or buckling of one or more of the strong force chains transmitting the deviatoric stress across the sample. While a larger sample would most likely not be as sensitive to such internal rearrangement of the contact force network, the results clearly indicate that a loss in internal stability can develop within a granular material under constant amplitude cycles of deviatoric stress. During each stress cycle there is plastic deformation in the form of frictional sliding at some of the contact points with resultant irreversible displacements at the contacts. These permanent displacements eventually cause a realignment of one or more strong force chains, triggering collapse. While the variations in strain in the intermediate sample were less substantial, there was also a measurable plastic response. This sample accumulated permanent strains around three times larger than the cyclic amplitude and also showed evidence of a local failure at about 4,200 cycles.

The coordination number, which indicates the number of contacts per particle, appears to vary in a consistent manner for all three simulations as illustrated in Fig. 7. For the simulations with cyclic stress amplitudes of $\Delta \mathrm{t}=0.03 \mathrm{~s}^{\prime}$ and $\Delta \mathrm{t}=0.02 \mathrm{~s}^{\prime}$, the coordination number increased rapidly during the initial number of cycles, indicating an initial adjustment in the contact force network. Then, over subsequent cycles, a steady but much more gradual increase in coordination number was observed with some fluctuations. The variation in coordination number indicates the plasticity of the response cannot be attributed only to sliding at contact points, but that there was a change in contact configuration involving both gain and loss of contacts. The increase in coordination number observed might appear to indicate the development of a stable network that should increase the stability of the system as a whole. However, the overall sample response indicated obvious instabilities in the simulation with $\Delta \mathrm{t}=0.04 \mathrm{~s}^{\prime}$ and these are less evident from the coordination number data. The coordination number calculated

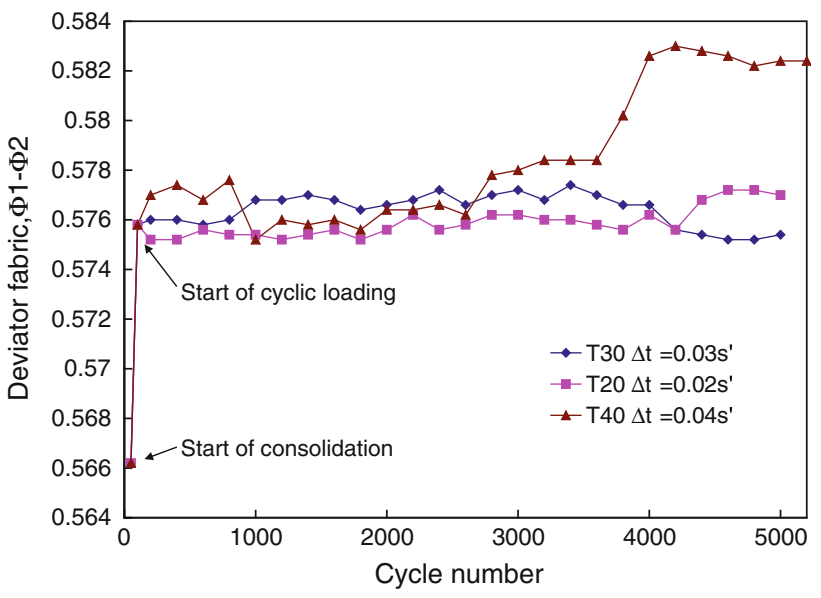

Fig. 8 Variation in deviatoric fabric during cyclic loading for different stress amplitudes

here considered all the contacts in the system, irrespective of the magnitude of the contact force transmitted. The results suggest that a better measure of stability may be one that can identify the "strong" contacts that form the dominant load transmitting columns or force chains in the material. There were less fluctuations in the coordination number for the samples subject to smaller amplitude load cycles.

The variation in deviator fabric during cyclic loading is illustrated in Fig. 8. All three tests had the same initial deviator fabric at the start of cyclic loading and this deviator fabric varied during the cyclic loading. For sample T20, which had a deviator stress amplitude of $\Delta \mathrm{t}=0.02 \mathrm{~s}^{\prime}$ the deviator fabric varied by only a small amount, with random small oscillations about the initial value being observed. For sample T30, with a deviator stress amplitude of $\Delta t=0.03 s^{\prime}$, there was a more notable variation in the magnitude of the deviator fabric, however no clear trend is evident. Initially the deviator fabric increased and then after about 4,000 cycles it decreased. For the sample with the largest magnitude of deviator stress, i.e. $\Delta \mathrm{t}=0.04 \mathrm{~s}^{\prime}$ the variation in $\Phi_{1}-\Phi_{2}$ was more significant. Following the most significant internal adjustment after about 4,000 cycles there was a clear increase in the deviator fabric. It is interesting that this marked change in deviator fabric occurred without a variation in the applied stresses conditions. Note that prior studies (e.g. Oda et al. (1985)) found the anisotropy of the contact normal orientations to be dependant on the stress conditions with the principal axes of the fabric tensor rotating in response to a rotation of the principal stresses during the course of deformation.

\section{Conclusions}

A series of DEM simulations was carried out to investigate the micromechanics of granular material under stress controlled cyclic loading. The effects of the consolidation process, contact stiffness ratio, and cyclic amplitudes were 
studied. While the 2D disk samples considered in this study should only be considered to be an analogue to real soil, some useful insight has been gained. The findings are as follows:

1. The samples considered had a packing configuration that was stable under gravitational loading, giving an inherent anisotropy in the contact normal orientations. When the sample was subsequently subject to isotropic consolidation, this inherent anisotropy reduced. However when the sample was subject to anisotropic consolidation, the anisotropy increased.

2. The ratio of the normal to tangential spring stiffnesses at the contact points (i.e. $\mathrm{k}_{\mathrm{n}} / \mathrm{k}_{\mathrm{s}}$ ) influenced the development of the deviator fabric development during isotropic consolidation. The sensitivity to this ratio can be attributed to the distribution of forces at the contact. Estimating the ratio of normal to shear stiffnesses at the contact between real soil particles is difficult. The sensitivity of the response presented here to this ratio indicates that it may be worthwhile to establish the sensitivity of the observed DEM model response to this parameter in future DEM studies.

3. The initial anisotropy following consolidation and prior to the initiation of cyclic loading impacted the strain accumulation during cycling. For samples with a greater initial deviator fabric, there was a greater increase in permanent axial strain in comparison with the samples whose fabric had been somewhat erased by isotropic consolidation.

4. The amplitude of the cyclic loading can influence the macro-scale material response (i.e. the strain accumulation) as well as the particle scale response (i.e. the development of an anisotropic fabric)in the soil.

These preliminary results indicate that even small amplitude cyclic loading can gradually cause measureable changes to the material structure. The simulations presented here consider a simple, two-dimensional material analogue of a real soil. Further simulations in three dimensions with more particles and more realistic contact models and particle geometries are needed to draw more definite conclusions about cyclic behavior of soil. A key point to consider is the specimen state (position relative to critical state line, which depends on void ratio and stress level). This research considered dense specimens; loose specimens could be attained by using the under compaction specimen generation approach proposed by Jiang et al. [29].

Acknowledgements The authors appreciate the support from the Geotechnical Laboratory of Imperial College London. The work is financially supported by National Natural Science Foundation of China with Grant No. 10922158 and No. 50978231, and by Open fund from Key Laboratory of Geotechnical and Underground Engineering of Ministry of Education, Tongji University, No. KLE-TJGE-0803
Open Access This article is distributed under the terms of the Creative Commons Attribution Noncommercial License which permits any noncommercial use, distribution, and reproduction in any medium, provided the original author(s) and source are credited.

\section{References}

1. Lekarp, F., Isacsson, U., Dawson, A.: State of the art I: resilient response of unbound aggregates. ASCE J. Trans. Eng. 126, 6675 (2000)

2. Sweeney, M., Lambson, M.:Long term settlements of storage tanks on sand. In: Proceedings Xth ECSMGE, Florence, Publication AGI, vol. 2, pp. 587-592 (1991)

3. Clayton, C.R.I., Xu, M., Bloodworth, A.: A laboratory study of the development of earth pressures behind integral bridge abutments. Geotechnique 56, 561-572 (2006)

4. Tedd, P., Charles, J.A., Holton, I.R., Robertshaw, A.C.: The effect of reservoir drawdown and long-term consolidation on the deformation of old embankment dams. Geotechnique 47(1), 33-48 (1997)

5. Janbu, N., Senneset, K.: Settlements due to drained, cyclic loads. In: International Conference on Soil Mechanics and Foundation Engineering, 10, Stockholm, June 1981, Proceedings 1, 165-170 (1981)

6. Jardine, R.J, Standing, J.R, Chow, F.C.: Some observations of the effects of time on the capacity of piles driven in sand. Geotechnique 55(4), 227-244 (2006)

7. Oda, M., Nemat-Nasser, S., Konishi, J.: Stress-induced anisotropy in granular masses. Soils Found. 25(3), 85-97 (1985)

8. Cosgrove, E.F., Lehane, B.M., Ng, C.W.W.: Sand tested under cyclic triaxial conditions with constant radial stress. In: International Conference on Soil Mechanics and Geotechnical Engineering, 15: The first International Conference of the Third Millennium, Istanbul, August 2001, Proceedings 1, 63-66 (2001)

9. AnhDan, L.Q., Koseki, J.: Effects of large number of cyclic loading on deformation characteristics. Soils Found. 44(3), 115-123 (2004)

10. Wichtmann, T., Niemunis, A., Triantafyllidis, Th.: Strain accumulation in sand due to cyclic loading: drained cyclic tests with triaxial extension. Soil Dyn. Earthq. Eng. 27(1), 42-48 (2007)

11. Wichtmann, T., Triantafyllidis, Th.: Influence of a cyclic and dynamic loading history on dynamic properties of dry sand, part II: cyclic axial preloading. Soil Dyn. Earthq. Eng. 24, 789-803 (2004)

12. Festag, G., Katzenbach, R.: Material behaviour of dry sand under cyclic loading. In: International Conference on Soil Mechanics and Geotechnical Engineering, 15: The First International Conference of the Third Millennium, Istanbul, Proceedings 1, 87-90 (2001)

13. Hyde, A.F.L, Higuchi, T., Yasuhara, K.: Postcyclic recompression, stiffness, and consolidated cyclic strength of silt. J. Geotech. Geoenviron. Eng. 133(4), 416-423 (2007)

14. Papadimitriou, A.G., Bouckovalas, G.D.: Plasticity model for sand under small and large cyclic strains: a multiaxial formulation. Soil Dyn. Earthq. Eng. 22, 191-204 (2002)

15. Cundall, P., Strack, O.: A discrete numerical model for granular assemblies. Geotechnique 29(1), 47-65 (1979)

16. David, C.T., Garcia-Rojo, R., Herrmann, H.H., Luding, S.: Hysteresis and creep in powders and grains. In: Garcia-Rojo, R. (ed.) Powders and Grains 05, vol. 1, pp. 291-294 (2005)

17. O’Sullivan, C., Cui, L., O'Neill, S.C.: Discrete element analysis of the response of granular terials during cyclic loading. Soils Found. 48, 511-530 (2008)

18. Satake, M.: Constitution of mechanics of granular materials through graph representation, Theoretical and Applied Mechanics 26, p. 257. University of Tokyo Press, Japan (1978) 
19. Rothenburg, L., Bathurst, R.J.: Analytical study of induced anisotropy in idealized granular materials. Géotechnique 39, 601614 (1989)

20. Oda, M.: Fabric tensor for discontinuous geological materials. Soils Found. 22(4), 96-108 (1982)

21. Thornton, C.: Numerical simulations of deviatoric shear deformation of granular media. Geotechnique 50(1), 43-53 (2000)

22. Thomas, P.A.: Discontinuous deformation analysis of particulate media. PhD thesis, Department of Civil Engineering, University of California, Berkeley (1997)

23. O'Sullivan, C., Bray, J.D., Riemer, M.F.: Influence of particle shape and surface friction variability on response of rod-shaped particulate media. ASCE J. Eng. Mech. 128, 1182-1192 (2002)

24. Marketos, G., Bolton, M.: Flat boundaries and their effect on sand testing. Int. J. Numer. Anal. Methods Geomech. 34(8), 821837 (2010)
25. Bardet, J.P., Proubet, J.: A numerical investigation of the structure of persistent shear bands in granular media. Géotechnique 41, 599613 (1991)

26. Cheung, G., O'Sullivan, C.: Effective simulation of flexible lateral boundaries in two- and three-dimensional DEM simulations. Particuology 6, 483-500 (2008)

27. Yimsiri, S., Soga, K.: Micromechanics-based stress \pm strain behaviour of soils at small strains. Geotechnique 50(5), 559-571 (2000)

28. Itasca Consulting Group: User Manual for PFC 2D (2003)

29. Jiang, M.J., Konrad, J.M., Leroueil, S.: An efficient technique for generating homogeneous specimens for DEM studies. Comput. Geotech. 30(5), 579-597 (2003) 